Open Access

\title{
Opportunities for peak shaving the energy demand of ship-to-shore quay cranes at container terminals
}

\author{
Harry Geerlings ${ }^{{ }^{*}}$, Robert Heij ${ }^{\wedge}$ and Ron van Duin ${ }^{2,3}$
}

\begin{tabular}{l}
\hline * Correspondence: Geerlings@essb. \\
eur.nl \\
'Deceased \\
${ }^{1}$ Erasmus University Rotterdam, \\
Erasmus School of Social and \\
Behavioural Sciences/ Erasmus \\
Smart Port, P.O. box 1738, 3000 DR \\
Rotterdam, The Netherlands \\
Full list of author information is \\
available at the end of the article
\end{tabular}

\begin{abstract}
This paper presents the results of both a qualitative and a quantitative study on the possibilities for peak shaving the energy demand of ship-to-shore (STS) cranes at container terminals. The objective is to present an energy consumption model that visualizes the energy demand of STS cranes and to show the possibilities for reducing the peak demand of STS cranes by implementing rules of operation (i.e. changes to the business operational procedures). The results show that the peak demand (and peak-related costs) can be reduced by 50\%, with an increase in the handling time of containerships of less than half a minute per hour handling time. This can be achieved by reducing the maximum energy demand of all operating STS cranes or by limiting the maximum number of simultaneously lifting STS cranes. If (one of) these rules of operation is implemented, an intermediate container terminal with six to eight STS cranes can save up to $€ 250,000$ per year, which is about $48 \%$ of total peak-related energy costs.
\end{abstract}

Keywords: Peak shaving, Container terminals, Electricity demand, Energy consumption, Ship-to-shore cranes

\section{Introduction}

\section{Growth in containerized transport}

The worldwide throughput of containers is growing continuously. The standardized size of containers (in $20 \mathrm{ft}$. and $40 \mathrm{ft}$. equivalent units) makes them a suitable means for transporting all kinds of products, ranging from multimedia and building materials to clothing and shoes. Even temperature-sensitive goods like flowers, fruits, and vegetables can be transported easily by temperature-controlled containers, known as reefers. The share of containerized transport in seaborne trade increased from $2.75 \%$ in 1980 to $15 \%$ in 2014 (UNCTAD 2015.), and total seaborne trade increased to 9842 million tons (UNCTAD 2015). The annual worldwide transport of containers increased from 28.7 million twenty-foot equivalent units (TEU) in 1990 to 171 million TEU in 2014 (UNCTAD 2015) The 20-year average growth percentage of the container market is a remarkable 7.8\% (Clarksons 2015; Port of Rotterdam 2015).

An important development that facilitates the growing container market is the increasing capacities of containerships. Whereas the largest containership in 1980 had

(c) The Author(s). 2018 Open Access This article is distributed under the terms of the Creative Commons Attribution 4.0 International License (http://creativecommons.org/licenses/by/4.0/), which permits unrestricted use, distribution, and reproduction in any medium, provided you give appropriate credit to the original author(s) and the source, provide a link to the Creative Commons license, and indicate if changes were made. 
a capacity of $3000 \mathrm{TEU}$, the largest containerships operating in 2015 have a capacity of almost 20,000 TEU (Lloyd's List 2015).

The growing size of containerships influences container terminal operations, as the number of containers per containership has also increased as a result of this development. Container carriers demand that container terminals handle their ships as fast as possible to continue their journey to the next port. This higher productivity is achieved by more automated terminal processes (Grunow et al. 2005) and by deploying more terminal equipment simultaneously. However, with more and more simultaneously operating ship-to-shore (STS) cranes, the energy demand (kW/s) increases. This also increases the highest observed peak demand, leading to a higher energy bill and therefore higher handling costs.

Container terminals' peak demand is responsible for about $25-30 \%$ of the monthly energy bill (Personal communication, ABB, a worldwide provider of electrotechnical solutions for the shipping, offshore, and harbour industries (ABB 2014; Stedin 2014). The main reason is that the highest observed peak demand is charged for the next 12 months. To illustrate this: if the highest peak in January is $12,000 \mathrm{~kW}$, the terminal is charged for 12,000 $\mathrm{kW}$ for the rest of the year. However, if the highest peak in March is $14,000 \mathrm{~kW}$, the terminal is charged for $14,000 \mathrm{~kW}$ until March the year after. A lower peak demand could result in large annual savings for container terminals. It is consequently very important to investigate the possibilities of reducing this peak demand.

\section{The research question}

The research objective is therefore to investigate the possibilities for peak shaving the electricity demand at container terminals by applying new rules of operation for electricity-consuming terminal processes, while also monitoring the consequences for the handling speed of containerships. Peak shaving implies the lowering of the highest observed peak in energy demand to reduce the energy-related costs. This enables container terminals to lower the handling costs of containerships, giving them a better competitive position. Another advantage of peak shaving is that terminals' energy demand is more stable; this is especially important for container terminals in countries where grid operators cannot prepare the energy system for unexpected high energy peaks. The handling time for containerships needs to be monitored, because extra handling time might affect a terminal's competitive position. The main research question addressed in this research is: What are the possibilities for reducing the peak demand of electricity-consuming terminal equipment (peak shaving) in order to reduce the electricity-related energy costs? The hypothesis is that, by implementing different rules of operation (i.e. process improvements), like limiting the number of lifting cranes or the maximum allowed energy, terminals are able to reduce the height of peaks and thereby reduce their energy-related costs.

This paper presents the results of this research by discussing STS cranes' terminal operations and the volatility of their energy demand in section 2 . Both the methodology applied and the study's relevance are presented in this section as well. Section 3 presents the energy consumption model, which forms the basis for the simulation model developed. The simulation model is presented in section 4, and the results of the simulation study are discussed in section 5. Finally, the 
implications of these results and the conclusions of the study are discussed in sections 6 and 7.

\section{Research and methodology STS crane operations}

After a containership has berthed at the seaside of a terminal, the STS cranes start unloading the incoming containers according to the unloading plan. STS cranes can use a normal spreader, enabling them to handle one container at a time, or more advanced spreaders (e.g. the twin-lift and tandem-lift) to handle multiple containers at the same time (Stahlbock and Voß 2008). The Super Post Panamax STS cranes, the current standard for unloading the largest containerships, are able to make approximately 32 lifts per crane per hour (APM Terminals 2014). This allows an STS crane to handle 32-64 TEUs per hour with a normal spreader and up to 128 TEUs per hour with a tandem-lift spreader.

The handling capacity of a container terminal is highly dependent on the number of STS cranes and their capacity, as the cranes determine the handling time per ship as well as the throughput of containers to the stacking process (Eugen et al. 2014).

During the (un)loading of a containership, two criteria are important: the ship's stability and the number of unproductive moves (Imai et al. 2006). During (un)loading, the ship's stability changes as a result of the continuously changing container load. Because containerships visit several container terminals, each time unloading containers from and loading containers onto the ship, not all containers that have to be unloaded are positioned on top of the ship's stacks. Ships therefore have to be loaded in an efficient way, allowing the next container terminal to unload the containership with a minimum of unproductive moves.

These two criteria are often in conflict, because the most efficient loading (regarding the minimization of unproductive moves) might not be in line with the most efficient loading regarding the ship's stability. This makes stowage very complex (Bortfeldt and Gehring 2001; Steenken et al. 2004; Dekker et al. 2006), especially because the stowage plans have to be aligned over all the different ports that have to (un)load the ship (Wilson and Roach 2000).

\section{Volatility of energy demand}

The STS cranes are connected to the electricity network. For all quay crane processes (moving of crane and spreader, crane lighting, and auxiliary processes), electricity is supplied by the network. Vertical movements have the most volatile energy demand, showing high peaks for hoisting the crane spreader and low falls for lowering the spreader, as can be seen in Fig. 1 (MSC Terminal Valencia 2009, field data). The gantry (horizontal) movements and auxiliary energy consumption are less volatile in character.

In Fig. 2, the total energy consumption for one STS crane is visualized. In total, two peaks can be identified for handling a container: the first for lifting a spreader and container above the ship and the second for lifting the spreader after the container is positioned in the terminal. When all STS cranes in a terminal are lifting at the same moment, the potential peak demand is very high. It is therefore important to visualize 


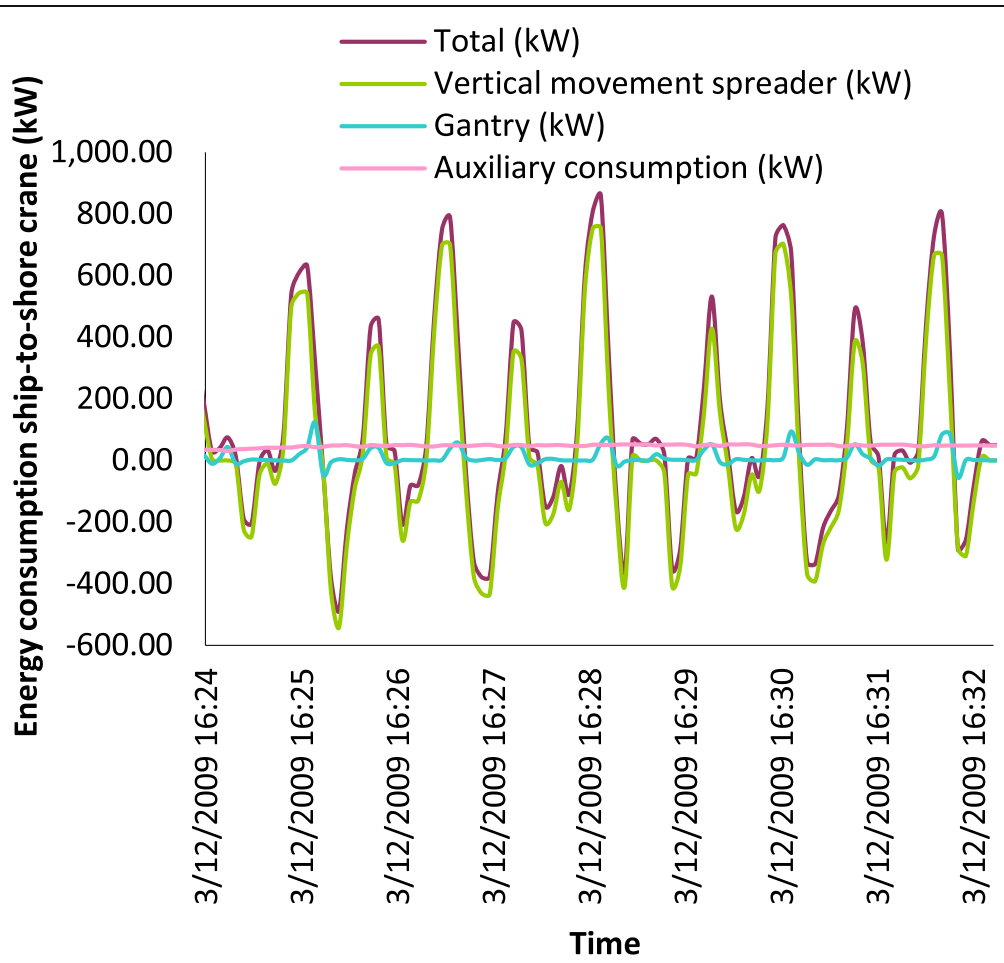

Fig. 1 Detailed energy consumption of quay crane (MSC Terminal Valencia 2009, field data)

the peak demand of a terminal while it is handling a containership and to investigate the opportunities to reduce the peak demand.

\section{Challenge for container terminals}

The growing need for container terminals to handle containerships as fast as possible leads to more automation and more simultaneously operating STS cranes, leading to high peaks in electricity demand. As discussed in section 1.1, because an observed peak demand is charged for the next 12 months, the highest peak is responsible for nearly $25-30 \%$ of the total electricity costs. This implies that higher handling speeds of containerships result in more peak-related energy costs, leading to higher handling costs. Because container carriers require both higher handling speeds and lower handling

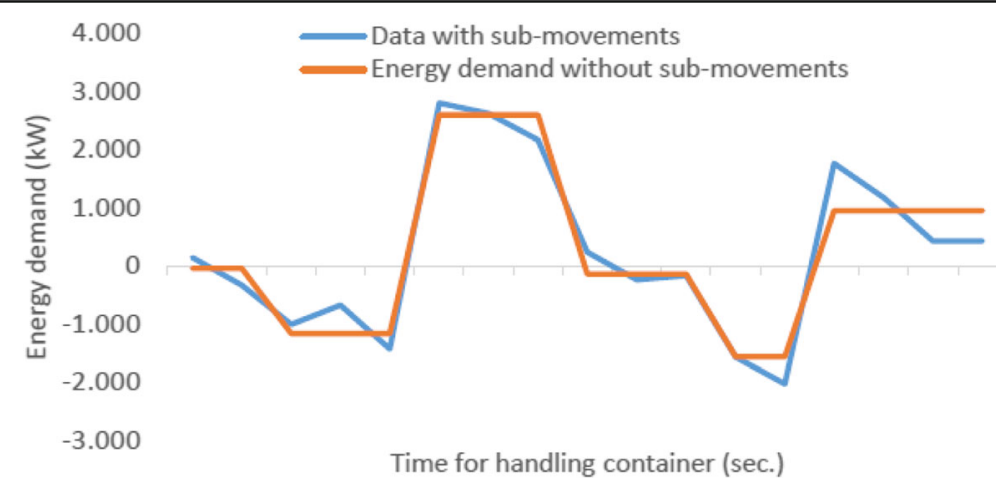

Fig. 2 Detailed energy consumption for handling one container (ABB 2014) 
costs, terminals are confronted with a dilemma. The challenge is therefore to find opportunities to reduce the peak-related costs without reducing the handling speed too much.

\section{Relevance}

\section{Scientific relevance}

The equipment at container terminals needs to be employed optimally by minimizing the completion time for handling containers, because a vessel's turnaround time is the key performance indicator for terminal operators (De Koster et al. 2009; Bierwirth and Meisel 2010). In the literature, this is classified as a scheduling problem in which a number of jobs (e.g. containers) are assigned to available resources such as cranes and vehicles transporting containers between the quayside area and the stacking area. Because of the complexity of container terminal operations, scheduling problems in a particular area are investigated to simplify the scheduling of the overall terminal (Geerlings et al. 2018).

For the quayside area, quay crane scheduling determines the sequence in which the STS cranes handle jobs and the time points at which these are performed (Kim and Park 2004; Meisel 2009; Liang et al. 2009; Zhang and Kim 2009; Diabat and Theodorou 2014), given different objectives and various operational constraints. Although the landside is not directly related to the quayside operation, the yard crane scheduling of a single block (Ng and Mak 2006; Gharehgozli et al., 2014a; Gharehgozli et al., 2014b) and of multiple blocks (He et al. 2010; Chen and Langevin 2011) have been studied in order to improve the operational efficiency of the stacking area. Cao et al. (2010) consider the integrated scheduling of the quayside transport area and the stacking area. Furthermore, the quayside area, the quayside transport area, and the stacking area together account for the transport of containers between the vessel and the stack, and therefore the integrated scheduling of these three areas has been investigated (Meersmans and Wagelmans 2001; Chen et al. 2007; Meier and Schumann 2007; Lau and Zhao 2008; Meisel (2009); Chen et al. 2013). In general, one can conclude from this literature review that the equipment scheduling problem aims at minimizing the completion time of all jobs in order to reduce vessel turnaround time. Scheduling problems are mainly concerned with productivity improvement without any consideration of creating energy efficiency at terminals.

Previous research on the energy consumption of container terminals (Van der Voet 2008; Geerlings and van Duin 2011; Van Duin and Geerlings 2011) does not provide a visualization of the peak demand of container terminals or STS cranes. The current research makes two contributions to science.

1. The first scientific contribution is the development of an energy consumption model that can show energy demand over time (in $\mathrm{kW} / \mathrm{s}$ ). Over recent years, many studies have been undertaken on the energy efficiency of container terminals. The models presented in these studies try to describe the total energy consumption over a given time interval (mostly in $\mathrm{kWh}$ per year). However, to visualize the peak demand of container terminals, and in particular of STS cranes, a more advanced model needs to be developed. This consumption model can also be applied to visualize the energy demand of other types of cranes in different industries. 
2. The second contribution is to present rules of operation that contribute to the reduction of peak demand at container terminals and to test these rules of operation by undertaking a case study to show the opportunities for peak shaving the energy demand of STS cranes.

Although we have observed in literature that dividing the whole process into sub-planning processes can lead to undesirable results and sub-optimal solutions (Meier and Schumann 2007), the research focus is here mainly at the quay crane scheduling to identify whether energy and costs savings can be obtained. If the research shows significant savings the next step can be made by integrating the yard crane management.

\section{Business relevance}

The size of containerships is increasing continuously. The newest generation is able to carry almost 20,000 TEU. Container terminals are under high pressure to handle ships as fast as possible against a low price, to improve their competitive position. However, when more and more STS cranes are simultaneously executing a lifting movement, peak demand and energy-related costs increase. For an intermediate container terminal with eight STS quay cranes, the peak-related costs can account for up to $25-30 \%$ of total energy costs. The energy consumption model and rules of operation developed show the opportunities for container terminals to reduce these peak-related costs, while monitoring the consequences for handling time. This could save a terminal tens of thousands of euros per year.

\section{Methodology}

The research is executed in three different stages:

1. First, an extensive literature review is conducted on the container market and in particular STS crane operations. This leads to a better understanding of the problem and shows the importance of reducing the peak energy demand of STS cranes;

2. Based on the knowledge acquired, an energy consumption model is developed by introducing a conceptual model and a final consumption model (mathematical formula).

3. The conceptual model is applied to a container terminal, so rules of operation can be tested quantitatively on their ability to reduce peak energy demand. The simulation model is developed in a discrete-event environment, with the Simio software package (Simio, 2015). The discrete modeling approach enables the modeler to model the

containers as passive objects with a predefined behavior and to visualize the energy demand per second, as time continues on the basis of the occurrence of events. Other environments, like system dynamics or agent-based modeling, do not operate in all of these aspects. The discrete environment has been applied in earlier research, for example to model rail operations (Caballini et al. 2014), to model the time duration of handling activities (Cartenì and De Luca 2011), to model and test several 
container stacking algorithms (Borgman et al. 2010), and to model the container

flows within container terminals (Alessandri et al. 2007; Alessandri et al. 2008).

\section{Energy consumption model}

\section{Conceptual model}

The energy consumption of STS cranes is highly dependent on the different movements made by the crane. In total, six different general movements can be distinguished:

1. Moving spreader from quay to ship;

2. Lowering spreader at ship side;

3. Hoisting spreader at ship side;

4. Gantry (i.e. horizontal) movement from ship to shore;

5. Lowering spreader at quay side;

6. Hoisting spreader at quay side.

Each of these movements has its own energy consumption specifications. In addition to these different movements, it is important to include the auxiliary energy consumption. The auxiliary consumption is a fixed energy demand per hour, needed to keep the pressure on the crane and for equipment in the cabin and engine room. The auxiliary consumption is rather constant over time because the quay cranes are not turned off while in idle or off-shift state.

The conceptual model, visualized in Fig. 3, is built on the idea of different energy specifications per type of movement and state (as the auxiliary energy consumption is also consumed in idle state). For all STS cranes, the precise time at which a movement is executed has to be determined. At that point, the energy consumption (kW/ s) is added to the current energy consumption. The auxiliary energy consumption per STS crane is multiplied by the number of cranes and also added to the energy consumption, resulting in the total energy consumption for all STS cranes. If this is

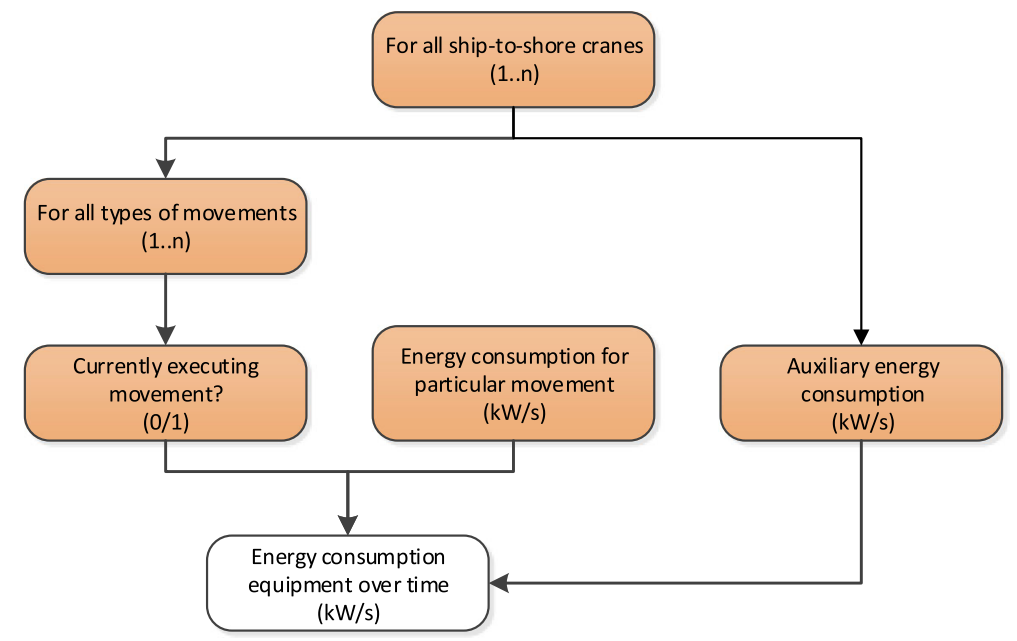

Fig. 3 Conceptual model for visualizing energy demand (kW/s) 
done every second, the energy consumption can be visualized over time, enabling the identification of peaks in energy demand.

\section{Energy consumption model}

The final energy consumption model is the mathematical representation of the conceptual model presented in Fig. 3. As shown in Eq. 1, the energy consumption is obtained by multiplying - for every STS crane separately - the energy consumption specifications for the movement that is currently being executed and by adding the auxiliary energy consumption.

Energy consumption container terminal per second (see Eq. 1):

$$
\sum_{h=1}^{H=4}\left(\sum_{i=1}^{I=4} m_{i h} * e_{i h l}\right)+a_{h}
$$

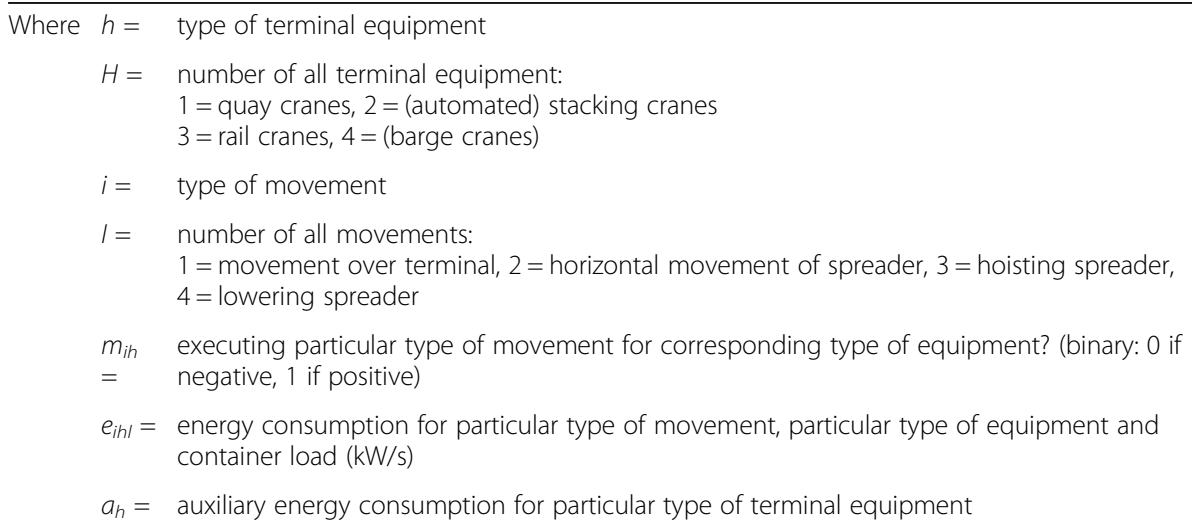

It should be mentioned here that the cranes are able to produce energy when dropping the container ( $m_{i h}$ is negative). However, the cranes in our study are not able to use the regenerated energy consumption or to store the temporary recovery energy. Therefore the variable $m_{i h}$ obtains a binary value 0 if the energy is negative. If this energy consumption model is applied over a longer period in time, the time aspect must be added to the formula. Eq. 2 shows the mathematical representation that can be used to visualize the energy demand of STS cranes over time.

Energy consumption container terminal per second for ( $\left.\mathrm{T}-\mathrm{T}_{0}\right)$ (see Eq. 2):

$$
\int_{t=0}^{T}\left(\sum_{h=1}^{H=4}\left(\sum_{i=1}^{I=4} m_{i h} * e_{i h l}\right)+a_{h}\right) d t
$$

\begin{tabular}{|c|c|c|}
\hline \multirow[t]{2}{*}{ Where } & $t=0=$ & starting time for measuring energy consumption \\
\hline & $T=$ & final time for measuring energy consumption \\
\hline
\end{tabular}

\footnotetext{
Where $h=$ type of terminal equipment

$H=$ number of all terminal equipment
} 


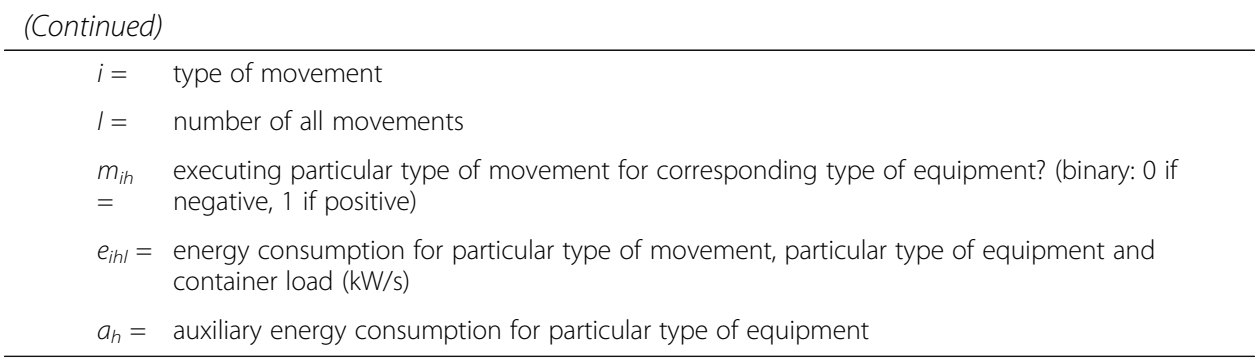

The energy consumption model is not only suitable for visualizing the energy demand of STS cranes; it can also be used for other crane operations at container terminals (e.g. automated stacking cranes and rail cranes), and even in different type of industries where cranes are used (e.g. factories or building sites).

\section{Application of consumption model Development of simulation model}

A discrete-event simulation model is constructed to apply the consumption model. When a containership arrives and is berthed, the terminal's quay cranes are able to start handling containers immediately. The quay cranes take the containers through six main processes (i.e. movements, see Fig. 4):

- Moving spreader horizontally from quay (idle position) to ship;

- Lowering spreader above ship to get a container;

- Lifting spreader and container from ship;

- Moving spreader and container horizontally from ship to quay side;

- Lowering spreader and container to terminal truck on quay side;

- Lifting spreader from quay (to idle position).

Every movement is divided into two or three sub-movements to give a more detailed outcome of the energy demand. For each movement, a container has its own process times and corresponding energy consumption specifications (ABB 2014). After the quay crane processes the container through all movements, the container is picked up by a terminal truck, bringing the container to the stacking area. Because the terminal trucks are dieselpowered, this process does not influence the peak electricity demand. For each crane, all 18 processes can be observed in the screen views of the simulation model (see Fig. 5a and b).

The model is able to generate the following relevant output:

- Energy consumption per second $(\mathrm{kW} / \mathrm{s})$;

- Handling time for containers (seconds);

- Number of active quay cranes;

- Number of lifting quay cranes;

- Number of containers paused and their average pausing time (due to limitations imposed by the rules of operation).

In Fig. 5a/b, a 3D/2D view of the simulation model is given. Here, eight quay cranes are transporting the containers (red triangles) through the different (sub)movements. Each 


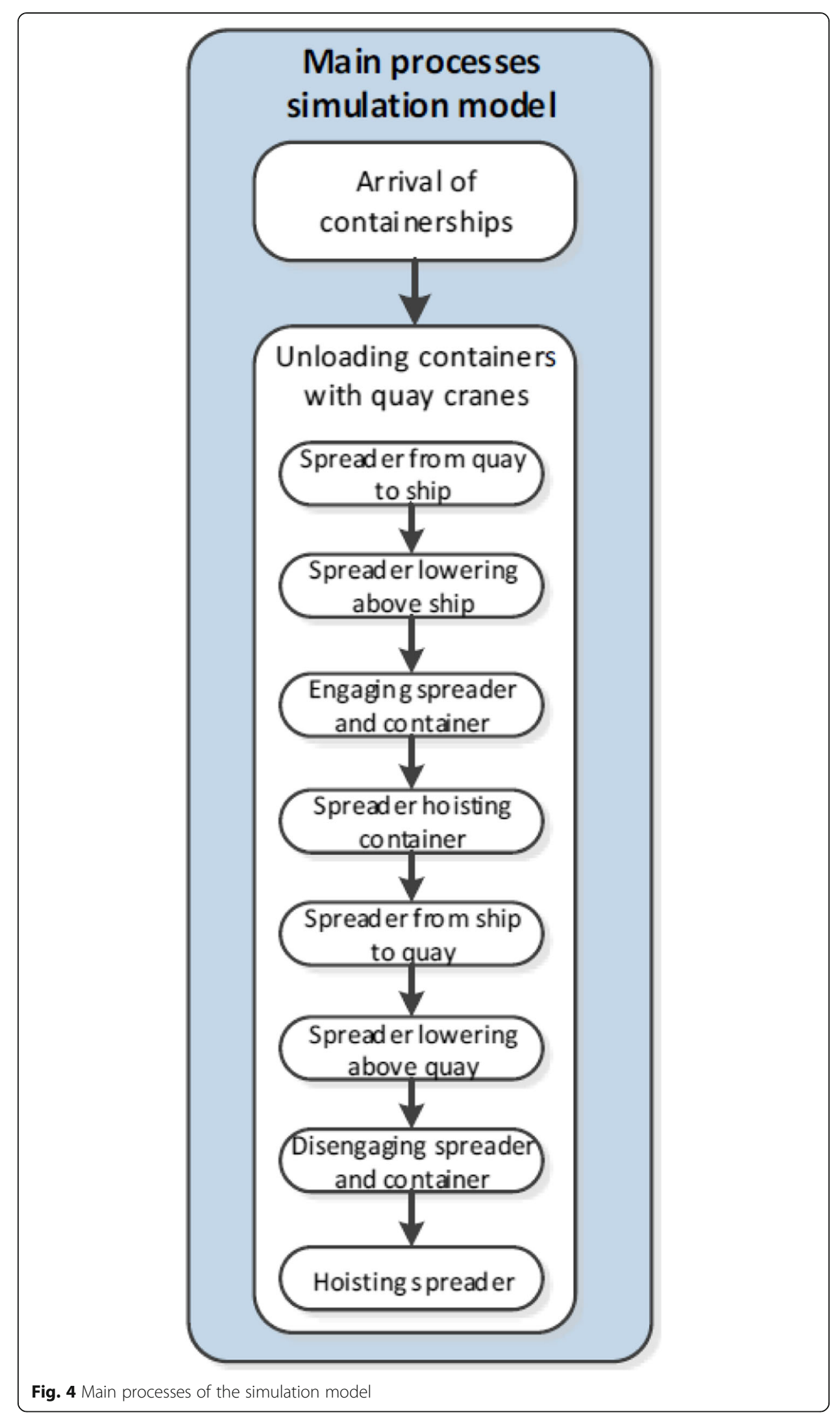




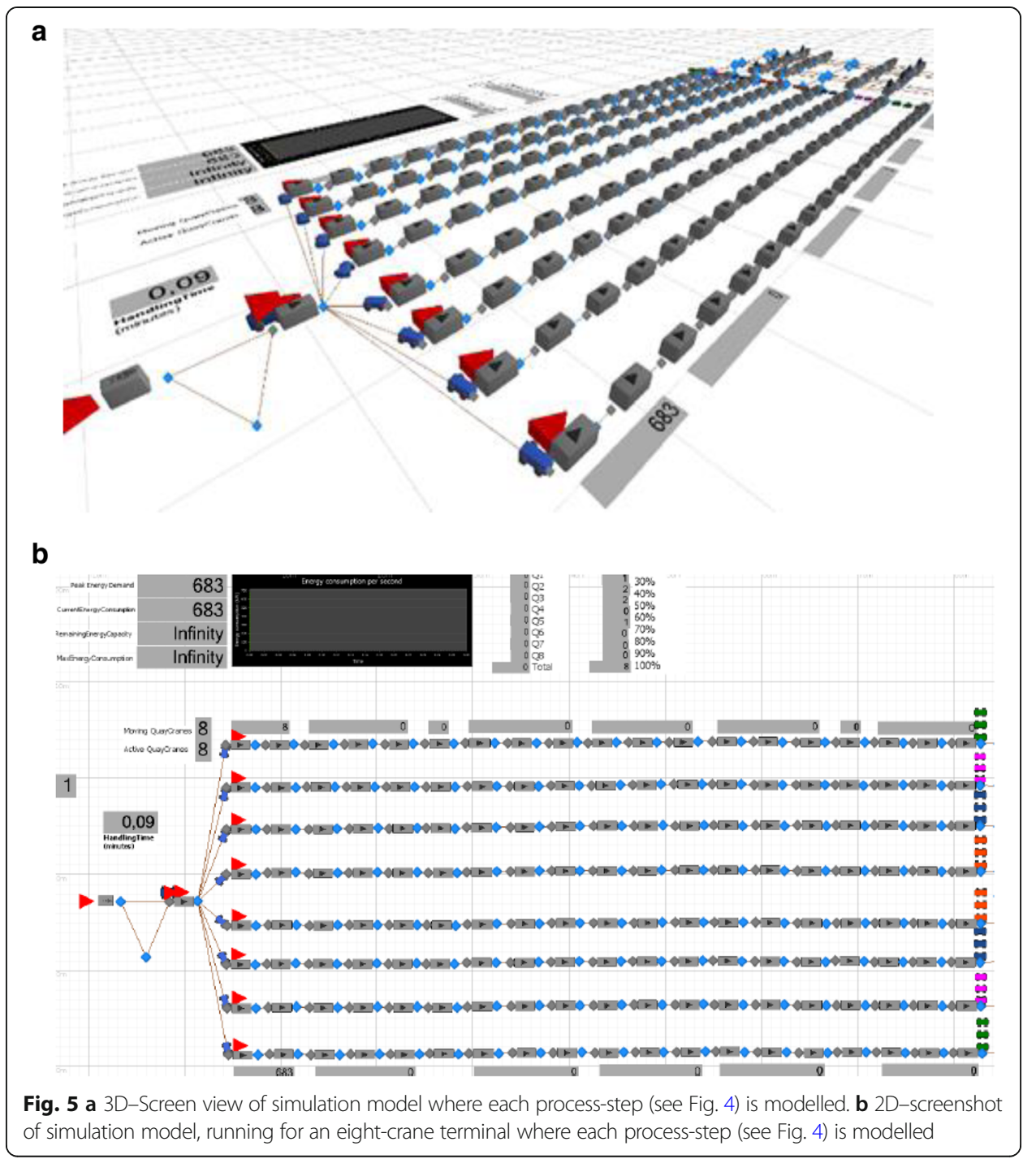

sub-movement is depicted as following an activity block. The activity block takes some operational time and consumes/produces some energy according the specifications. The auxiliary equipment is also modeled because the cranes cannot operate on their own and need additional vehicles to move the containers to the stack. The results of the simulation model are verified with real data and by expert opinion (ABB 2014).

\section{Rules of operation}

The rules of operation that are implemented need to be seen as process improvements to reduce the peak demand for STS cranes. In total, two rules of operation are implemented in the simulation model to test their impact on peak demand and handling time:

\section{Restrict number of lifting quay cranes}

The first rule of operation restricts the number of simultaneously lifting quay cranes because the lifting movements are the most energy-intensive movements (see section 2.2). 
When, for example, maximally four of the eight STS cranes are allowed to lift simultaneously, some cranes may need to stop operating temporarily, waiting until one of the other cranes finishes its lifting movement.

\section{Restrict maximal energy demand}

The second rule of operation restricts the maximal energy demand per second. Before starting a new movement, every STS crane requests the energy that it is expecting to consume (depending on the type of movement and container load). On the basis of this expected consumption, the simulation model looks at whether this demand is available. If not, the crane is asked to pause until there is enough demand left to start the movement.

\section{Validation of simulation model}

The rules of operation are applied for two types of container terminals (six and eight STS cranes) and a yearly throughput of 1.6 million TEU. The base scenario of the simulation model is executed with the standard specifications of the container terminal. This means that all eight quay cranes are handling containers, without any restrictions on the number of simultaneously lifting quay cranes or on maximum energy demand per second. The base scenario is run with 10 replications (more than the minimum desired eight replications, as calculated in the last sub-section). The time span is one week. During this week, 19 containerships arrive with a total of 20,114 TEU. Without implementation of one of the rules of operation, the peak demand is $19,230 \mathrm{~W}$ and peak-related energy costs are $€ 518,000$, based on the tariff of Dutch grid operator Stedin (2014). The average maximum energy demand of all replications is $19,177 \mathrm{~kW}$, with a minimum of $18,063 \mathrm{~kW}$ and a maximum of 20,004 $\mathrm{kW}$. The corresponding half width is $364.4 \mathrm{~kW}$. The handling time of all containers is $1857 \mathrm{~min}$, which is $31.0 \mathrm{~h}$.

The model is validated on three important aspects: container load, observed peak demand, and handling time. All three aspects are discussed below.

\section{Container load}

Each container load (0-100\%) has its own pre-defined energy specifications $(\mathrm{kW} / \mathrm{s})$. Multiplied by the operation times per sub-movement, the total energy consumption for a container can be determined and compared with real data. The result is that the maximum difference in energy consumption is $0.9 \%$. For most container loads, the difference is not larger than $0.2 \%$. Because the different container loads do not appear in the same proportion, the difference is multiplied by their appearance distribution (container mix). The result is a weighted difference of $0.26 \%$ (see Table 1), which might not be considered significant to the energy consumption results. The influence on the energy peak is difficult to calculate however, because it depends on the current container mix, which is changing continuously in the simulation model.

\section{Peak demand}

If the peak demand of the simulation (base scenario with eight lifting quay cranes and no restriction on the maximum energy demand per second) is compared, the peak demand lies around 20,000 kW. This is consistent with data for a terminal with eight 
Table 1 Weighted difference for difference in energy demand

\begin{tabular}{llll}
\hline Container load & Container mix & Difference & Weighted difference \\
\hline $0 \%$ & $12.5 \%$ & $0.00 \%$ & $0.00 \%$ \\
$20 \%$ & $32.0 \%$ & $0.20 \%$ & $0.06 \%$ \\
$30 \%$ & $11.1 \%$ & $0.35 \%$ & $0.04 \%$ \\
$40 \%$ & $11.4 \%$ & $0.16 \%$ & $0.02 \%$ \\
$50 \%$ & $13.6 \%$ & $0.00 \%$ & $0.00 \%$ \\
$60 \%$ & $13.6 \%$ & $0.90 \%$ & $0.12 \%$ \\
$70 \%$ & $3.3 \%$ & $0.42 \%$ & $0.01 \%$ \\
$80 \%$ & $1.6 \%$ & $0.21 \%$ & $0.00 \%$ \\
$90 \%$ & $0.6 \%$ & $0.00 \%$ & $0.00 \%$ \\
$100 \%$ & $0.3 \%$ & $0.00 \%$ & $0.00 \%$ \\
Total weighted average & & & $0.26 \%$ \\
\hline
\end{tabular}

quay cranes (ABB 2014); this validates the outcome of the simulation model on this aspect.

\section{Handling time}

The total run time for the base scenario is $171.0 \mathrm{~h}$ (one week plus three hours extra run time). The quay cranes are operating $18.0 \%$ of the time (half width $0.5 \%$ ), which is $30.8 \mathrm{~h}$. In this time frame, 10,057 containers are handled. If eight quay cranes are operating, this results in a handling time of $88.1 \mathrm{~s} /$ container.

The theoretical (weighted) handling time of a container (based on the appearance of each container load) is $91.4 \mathrm{~s} /$ container, a difference of $3.3 \mathrm{~s}$ (3.6\%). This difference could be explained by random distribution of process times for engaging the container in the simulation model, whereas the theoretical handling time makes use of standard process times instead of a distribution.

\section{Results}

\section{Results for limiting number of lifting quay cranes}

If the number of lifting STS cranes is reduced, the peak demand decreases, as shown in Fig. 6. What is striking is that the handling time does not increase in the same proportion. A reduction to four lifting cranes leads to an extra handling time of $0.37 \%$ (i.e. less than half a minute per hour). The handling time is not impacted that much

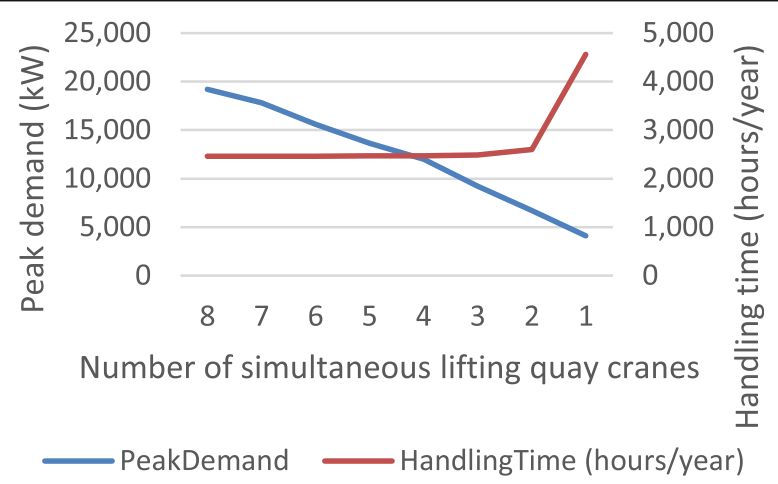

Fig. 6 Relation between peak demand and handling time when the number of lifting cranes is restricted 
because of the fact that the maximum peak demand with eight cranes (around $19,000 \mathrm{~kW}$ ) occurs only briefly. As shown by Fig. 7, for a peak demand of 19,000 kW, an energy demand of more than $9000 \mathrm{~kW}$ occurs only $1.1 \%$ of the time. Most of the time, the energy demand is lower than $9000 \mathrm{~kW}$.

As can be concluded from Fig. 6, restricting the number of simultaneously lifting quay cranes has a positive influence on reducing peak demand. If one looks at the impact on cost savings on the one hand and handling time on the other hand, one can see the most cost-effective scenario (i.e. yearly savings per extra second handling time) and the total cost reduction against a particular extra handling time.

The optimal cost-effective implementation is to reduce the number of lifting quay cranes to six (eight-crane terminal) or five (six-crane terminal) as can be seen in Fig. 8 . In these cases, the savings per extra second handling time are higher than for other scenarios.

If one looks at the total yearly savings against an extra handling time of less than $1.0 \%$, the number of quay cranes can be limited even more. In the case of an eightcrane terminal, this could result in a reduction to four lifting cranes. This saves $€ 195,000$, which is $39 \%$ of the peak-related costs. For a six-crane terminal, this would result in a reduction to three lifting cranes, which saves $€ 155,000$ (reducing total peak demand costs by $38 \%$ ).

\section{Results for limiting maximum energy demand}

To limit the maximum energy demand per second, the relation between the maximum allowed energy demand and handling time (see Fig. 9) is comparable to the situation where the number of simultaneously lifting STS cranes is limited. The maximum energy demand can be reduced by almost 50\% (from 19,000 kW to $9000 \mathrm{~kW}$ ), while the handling time increases by $0.1 \%$. Only by restricting the energy demand too much (to less than $6000 \mathrm{~kW}$ ) does the handling time increase by 3-45\%.

Restricting the maximum allowed energy demand has a positive influence on reducing terminals' peak demand. The influence on handling time is only minimal when the allowed energy demand is reduced by approximately less than $50 \%$, whereas it enables terminals to reduce their peak-related energy costs hugely.

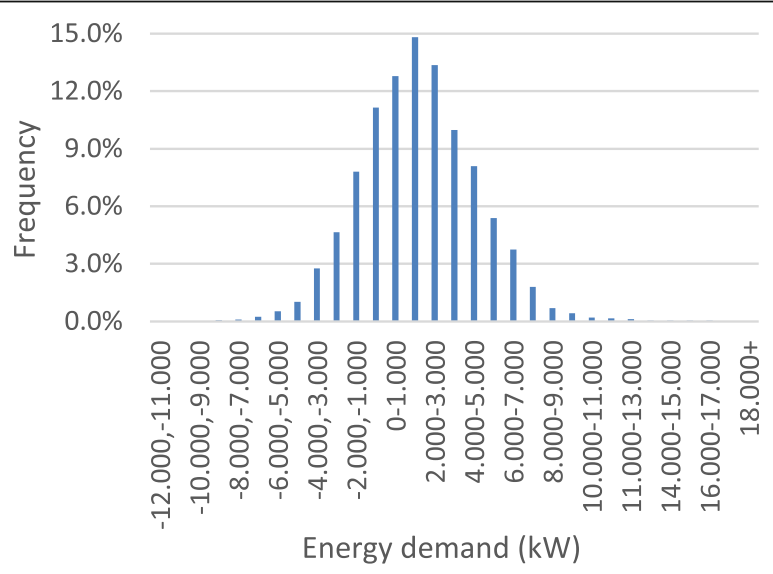

Fig. 7 Frequency (per 0.1 s) per energy demand interval 


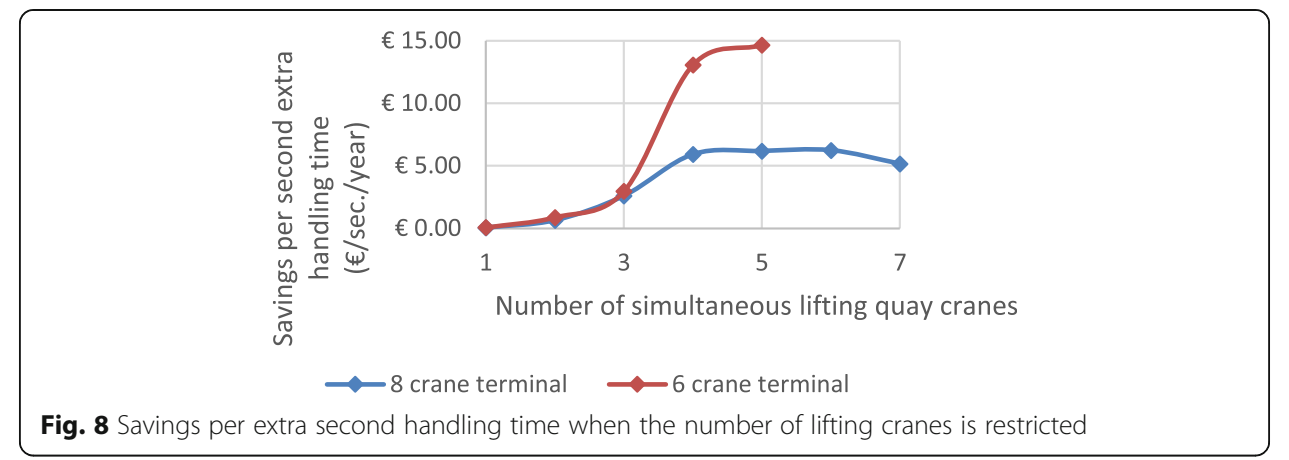

When the total savings per year are divided by the extra handling time needed to handle all containers on a yearly basis, the savings per second are obtained, as shown in Fig. 10. For the eight-crane terminal, there is a clear optimum if the maximum demand is reduced to $14,000 \mathrm{~kW}$. In this case, the savings are $€ 141,000$ per year, while the handling time is $0.01 \%$ faster. This results in a negative saving ${ }^{1}$ of $€ 197.10$ per second. Restricting the energy demand to $17,000 \mathrm{~kW}, 18,000 \mathrm{~kW}$, or $19,000 \mathrm{~kW}$ also results in a negative saving. However, in these cases, the total savings are only $€ 12,000$ to $€ 61,000$. Restricting the energy demand to $13,000 \mathrm{~kW}$ gives a saving of $€ 251.53$ per second, absolutely the highest saving seen.

For the six-crane terminal, the highest (negative) saving per second is obtained by reducing the maximum energy demand to $12,000 \mathrm{~kW}$ (-€180.27 per second) or $13,000 \mathrm{~kW}$ ( $€ 115.86$ per second), saving the terminal, respectively $€ 80,000$ or $€ 53,000$ per year. The highest positive value (meaning a saving against extra handling time) is achieved by reducing the energy demand to $11,000 \mathrm{~kW}$. This saves $€ 79.40$ per second against an extra handling time of $0.01 \%$ and a total cost saving of $€ 107,000$.

\section{Analyses of results}

The outcomes presented in subsections 5.1 and 5.2 show a clear result: it is possible to reduce peak energy demand, saving up to $€ 250,000$ per year against a little extra handling time (in some scenarios without extra handling time). The bigger the restriction of the rules of operation is, the larger the effect on the operations, as

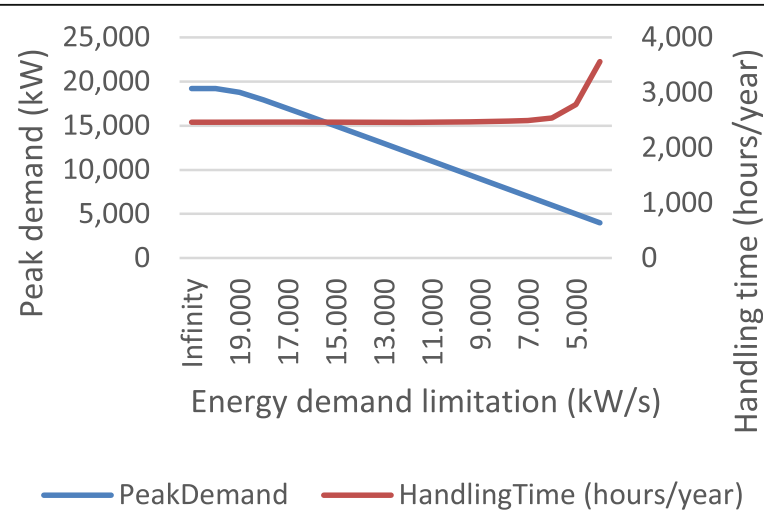

Fig. 9 Relation between peak demand and handling time when maximum energy demand is restricted 


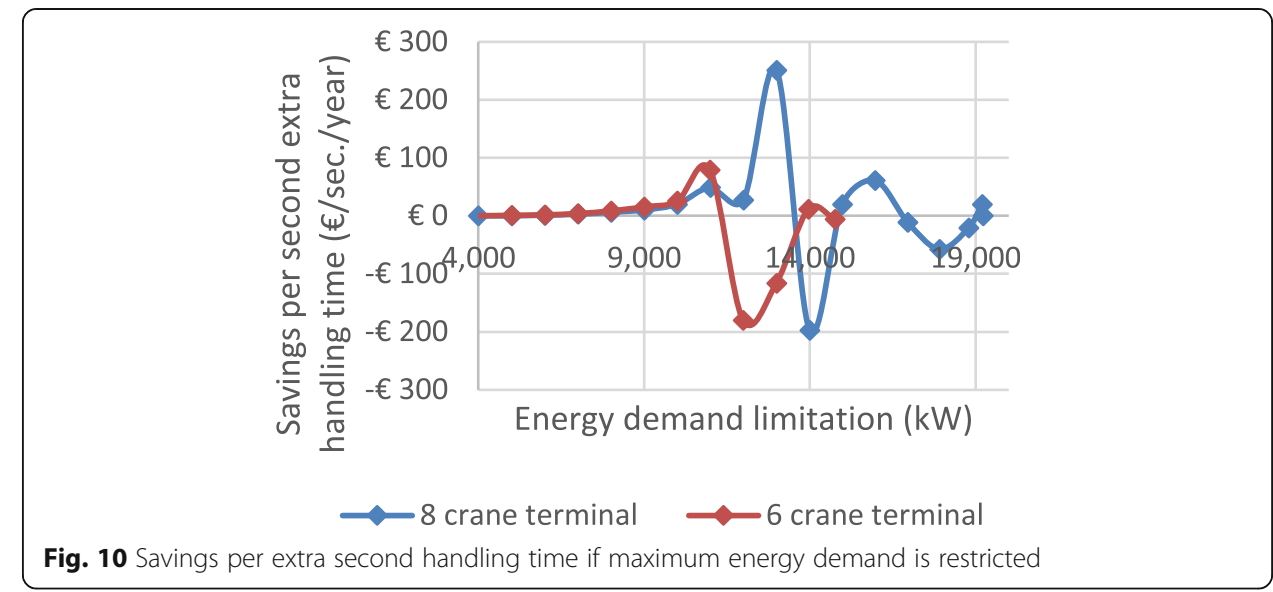

visualized by the number of temporarily delayed containers. However, since more and more container terminals are operating automatically, this can be integrated in the terminals' software. Delay of containers should not be a problem if one of the rules of operation is implemented.

Regarding total cost savings, the optimal solution is to reduce the maximum energy demand per second by $50 \%$ of the original highest observed energy demand. By doing this, $€ 160,000$ to $€ 249,000$ (40-48\% of peak-related costs) can be saved annually. The impact on terminal operations is small, as the extra handling time is only $0.1 \%$ and the number of temporarily delayed containers is $2.2-3.7 \%$. The savings per second are $€ 15.53$ to $€ 20.12$.

If the savings per second extra handling time are considered to be more important than the total annual savings (for example to compensate container carriers, see next section), the maximum energy demand can be reduced by $30-35 \%(13,000 \mathrm{~kW} / \mathrm{s}-14,000 \mathrm{~kW} / \mathrm{s})$ for an eight-crane terminal or by $5-15 \%$ for a six-crane terminal $(12,000 \mathrm{~kW} / \mathrm{s}-$ $13000 \mathrm{~kW} / \mathrm{s}$ ). Because the handling time is hardly affected, the extra savings per second are very high, especially because some of these scenarios showed a small quicker handling time against a restricted energy demand.

If the number of lifting quay cranes is reduced by $50 \%$, the peak-related costs are reduced by approximately $40 \%$ (saving up to $€ 195,000$ per year). The extra handling time is only $0.37-0.44 \%$ (less than half a minute per hour handling time) against a saving of $€ 2.96-€ 5.92$ per second extra handling time. By reducing the number of simultaneously lifting quay cranes by less than $50 \%$, the total savings are less, but the savings per second do not increase. By reducing the number of lifting quay cranes by more than $50 \%$, peak energy demand decreases even further, but the handling time increases drastically. The optimal solution would therefore be to reduce the number of simultaneously lifting quay cranes by $50 \%$.

\section{Implications of results}

\section{Extra handling time}

Extra waiting time for containerships is something that is viewed critically by container carriers. In contrast to the critical attitude of cargo carriers towards waiting time in ports, the adaption of containerships' cruising speeds (also known as slow steaming) is not seen as a problem. For container carriers, their biggest costs are fuel. These costs 
can be reduced by adapting the ship's speed: a reduction to $80 \%$ saves $60 \%$ of fuel costs, and a reduction to $60 \%$ saves $90 \%$ of fuel costs (Weismann 2010). A market survey has shown that $75 \%$ of the surveyed liners and carriers apply slow steaming in order to save bunker costs (Seatrade Global 2014). Because fuel costs are so high, container carriers operate more efficiently by sailing at lower speeds. In this regard, the extra travel time is compensated by fuel savings.

\section{Costs to containership}

To handle 2000 TEU of a containership (loading and unloading), a terminal needs approximately $18 \mathrm{~h}$ using only three quay cranes. When extra handling time is needed, the question is whether container carriers are willing to accept this without any form of compensation. If terminal operations take more time than agreed in advance, carriers are compensated; this is known as demurrage (Haugen Consulting 2015). When a ship requires less time than agreed beforehand, the terminal can request a bonus for quicker handling, the so-called despatch. This shows that compensation is quite regular in the shipping business.

The question is therefore whether container terminals are able to compensate container carriers to a certain extent. To answer this question, the costs for a containership must first be determined (see Table 2).

To determine the annual costs for a containership, AECOM (2012) drew up a report for the North Carolina Department of Transportation. It pointed out three cost aspects: the investment costs for a containership, labor costs, and fuel costs. The purchase of a 15,000 TEU containership (Emma Maersk class) costs around €127 million (Maersk 2006). If these costs are divided over a lifespan of 30 years at an annual discount rate of $6 \%$, this is $\pm € 9$ million per year. Labor costs can be estimated at $€ 1.2$ million (AECOM 2012). Fuel costs can be ignored, as extra handling time will not lead to extra fuel consumption.

As a peak energy reduction of $50 \%$ saves a container terminal at least $€ 2.96-5.92$ per second, this leaves room to compensate the carriers for the extra handling time. This could result in a win-win situation: container terminals saving costs by reducing their peak demand and carriers reducing their handling costs as a result of compensation.

\section{Conclusion}

The objective of this research was to investigate the opportunities for lowering the peak energy demand of STS crane operations at container terminals. If an attempt is made to reduce the peak energy demand of container terminals by implementing new rules of operation (i.e. reducing the number of simultaneously lifting cranes or limiting

Table 2 Cost containership per year, hour, and second

\begin{tabular}{ll}
\hline & Costs \\
\hline Investment costs & $€ 9000,000$ \\
Labor costs & $€ 1,200,000$ \\
Total per year & $€ 10,200,000$ \\
Total per hour & $€ 1164$ \\
Total per second & $€ 0.32$ \\
\hline
\end{tabular}


the maximum energy demand), it is shown that the peak can be reduced by $50 \%$ while impacting the handling time less than half a minute per hour. A cost reduction of $50 \%$ saves a container terminal with eight quay cranes and a throughput of 1.6 million TEU up to $€ 275,000$ per year.

Besides the positive effect of cost savings, the reduction of peak energy demand has consequences for the handling time. In most scenarios (depending on how much the number of simultaneously lifting cranes and energy demand per second is limited), the extra handling time would be less than half a minute per hour. The question is whether container carriers are willing to accept extra handling time. Container terminals need to be prepared to negotiate with container carriers about some sort of compensation. This could be financial, but might also relate to extra service (e.g. free electricity power for ships while berthed) or sustainability agreements. Irrespective of how costs are allocated, this research has shown that container terminals can reduce their peakrelated energy costs by managing their energy consumption in a smarter way.

Next research step is to study the integrated scheduling of the quayside area, the quayside transport area, and the stacking area together in order to evaluate the consequences of the new crane scheduling for the costs savings and container handling times (Wong and Kozan 2006; Boer and Saanen 2014).

\section{Endnotes}

${ }^{1}$ The negative cost saving per second is actually a positive result, because the handling time for this scenario is lower than for the standard situation, meaning that the cost savings (positive result) are divided by a negative extra handling time (i.e. less handling time).

\section{Acknowledgements}

On 7 June 2015, Robert Heij, co-author of this paper, passed away after 1 year of illness. Robert suffered from an aggressive form of cancer. During his illness, he was determined to complete his thesis and graduated. Robert's work (Heij 2015) was excellent, and he was nominated for the SmartPort 'best thesis award' in Rotterdam. On June 11, 1 day before his funeral, he was announced as the winner. We promised to continue his work. Therefore, in tribute to his memory, the other co-authors of this paper, Harry Geerlings and Ron van Duin, now dedicate this paper to Robert Heij.

Funding

there is no funding body in the design of the study and collection, analysis, and interpretation of data and in writing the manuscript should be declared.

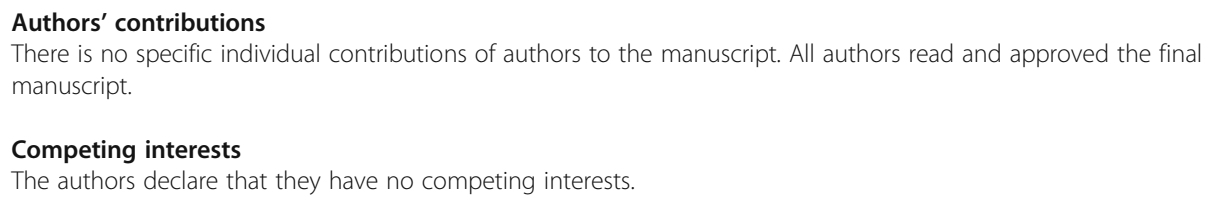


Alessandri A, Cervellera C, Cuneo M, Gaggero M, Soncin G (2008) Modeling and feedback control for resource allocation and performance analysis in container terminals. IEEE Trans Intell Transp Syst 9(4):601-614

Alessandri A, Sacone S, Siri S (2007) Modelling and optimal receding-horizon control of maritime container terminals. J Math Model Algorithms 6(1):109-133

APM Terminals, 2014. Terminal Information.

Bierwirth C, Meisel F (2010) A survey of berth allocation and quay crane scheduling problems in container terminals. Eur J Oper Res 202(3):615-627.

Boer CA, Saanen YA (2014) Plan validation for container terminals. In: Tolk A, Diallo SY, Ryzhov IO, Yilmaz L, Buckley S, Miller JA (eds) Proceedings of the 2014 winter simulation conference, at savannah, GA, USA, pp 1783-1794

Borgman B, van Asperen E, Dekker R (2010) Online rules for container stacking. OR Spectr 32(3):687-716

Bortfeldt A, Gehring H (2001) A hybrid genetic algorithm for the container loading problem. Eur J Oper Res 131(1):143-161

Caballini C, Pasquale C, Sacone S, Siri S (2014) An event-triggered receding-horizon scheme for planning rail operations in maritime terminals. IEEE Trans Intell Transp Syst 15(1):365-375

Cao JX, Lee D, Chen JH, Shi Q (2010) The integrated yard truck and yard crane scheduling problem: benders' decomposition-based methods. Transp Res E 46(3):344-353

Cartenì A, De Luca S (2011) Tactical and strategic planning for a container terminal: modelling issues within a discrete event simulation approach. Simul Model Pract Theory 21(1):123-145

Chen L, Bostel N, Dejax P, Cai J, Xi L (2007) A tabu search algorithm for the integrated scheduling problem of container handling systems in a maritime terminal. Eur J Oper Res 181(1):40-58

Chen L, Langevin A (2011) Multiple yard cranes scheduling for loading operations in a container terminal. Eng Optim 43(11):1205-1221

Chen L, Langevin A, Lu Z (2013) Integrated scheduling of crane handling and truck transportation in a maritime container terminal. Eur J Oper Res 225(1):142-152

Clarksons, 2015. Clarksons, the heart of global shipping. Retrieved from Containers: http://www.clarksons.com/services/ broking/containers/

De Koster R, Balk B, van Nus W (2009) On using DEA for benchmarking container terminals. Int J Oper Prod Manag 29(11):1140-1155

Dekker R, Voogd P, van Asperen E (2006) Advanced methods for container stacking. OR Spectr 28:563-586

Diabat A, Theodorou E (2014) An integrated quay crane assignment and scheduling problem. Comput Ind Eng 73:115-123

Eugen R, Şerban R, Augustin R, Ştefan B (2014) Transshipment modelling and simulation of container port terminals. Adv Mater Res 837:786-791

Geerlings H, Kuipers B, Zuidwijk R (2018) Port and networks; strategies, operations and perspectives. Routledge, Abingdon

Geerlings H, van Duin R (2011) A new method for assessing CO2-emissions from container terminals: a promising approach applied in Rotterdam. J Clean Prod 19(6-7), 657-666

Gharehgozli AH, Laporte G, Yu Y, De Koster R (2014a) Scheduling twin yard cranes in a container block. Transp Sci 49(3):686-705

Gharehgozli AH, Yu Y, de Koster R, Udding JT (2014b) An exact method for scheduling a yard crane. Eur J Oper Res 235(2):431-447

Grunow M, Günther H, Lehmann M (2005) Dispatching multi-load AGVs in highly automated seaport container terminals. In: Günther H, Kim K (eds) Container terminals and automated transport systems. Springer, Berlin, pp $231-258$

Haugen Consulting, 2015. What Is Demurrage? Retrieved from http://www.haugenconsulting.com/resources/what-isdemurrage/

He J, Chang D, Mi W, Yan W (2010) A hybrid parallel genetic algorithm for yard crane scheduling. Transp Res E 46(1):136-155

Heij, R., 2015. Opportunities for peak shaving electricity consumption at container terminals. Applying new rules of operation to achieve a more balanced electricity consumption. Master's thesis. Delft University of Technology, Delft

Imai A, Sasaki K, Nishimura E, Papadimitriou S (2006) Multi-objective simultaneous stowage and load planning for a container ship with container rehandle in yard stacks. Eur J Oper Res 171(2):373-389

Kim KP, Park YM (2004) A crane scheduling method for port container terminals. Eur J Oper Res 156(3):752-768

Lau HYK, Zhao Y (2008) Integrated scheduling of handling equipment at automated container terminals. Int J Prod Econ 112(2):665-682

Liang C, Huang Y, Yang Y (2009) A quay crane dynamic scheduling problem by hybrid evolutionary algorithm for berth allocation planning. Comput Ind Eng 56(3):1021-1028

Lloyd's List, 2015. MSC Oscar becomes the world's largest boxship. Retrieved from http://www.lloydslist.com/ll/news/ article453843.ece

Maersk, 2006. Emma Maersk/Container vessel specifications. Retrieved from http://www.emma-maersk.com/specification/

Meersmans PJM, Wagelmans APM (2001) Effective algorithms for integrated scheduling of handling equipment at automated container terminals, Technical report, econometric institute. Erasmus University Rotterdam, Rotterdam, The Netherlands

Meier L, Schumann R (2007) Coordination of interdependent planning systems, a case study. In: Koschke R, Herzog O, Roediger K, Ronthaler M (eds) Informatik, 2007, volume P-109 of lecture notes in informatics (LNI). Gesellschaft fur Informatik, Bremen, Germany, pp 389-396

Meisel F (2009) Seaside operations planning in container terminals. Berlin. Physica-Verlag, Germany

MSC Terminal Valencia. 2009. Energy consumption quay crane.

Ng WG, Mak KL (2006) Yard crane scheduling in port container terminals. Appl Math Model 29(1):263-276

Port of Rotterdam, 2015. Focus-on-Vessels-in-the-port-of-rotterdam.. Retrieved from https://www.portofrotterdam.com/ sites/default/files/Focus-on-Vessels-in-the-port-of-rotterdam.pdf at 15 June 2016

Seatrade Global, 2014. The economics of slow steaming. Retrieved from http://www.seatrade-maritime.com/news/ americas/the-economics-of-slow-steaming.html 
Simio LLC., 2015. Simio Simulation Software. http://www.anylogic.com/download-free-simulation-software-foreducation/?gclid=COHpw6uCyMsCFaqe2wod82IJSA

Stahlbock, R., Voß, S., 2008. Operations research at container terminals: a literature update. OR Spectrum 30(1), 1-52

Stedin, 2014. Electriciteit tarieven 2014 - aansluiting en transport voor grootverbruikers. Retrieved from http://www. stedin.net/zakelijk/ /media/files/stedin/tarieven/kv/stedin-voorbeeldnota-elektriciteit.pdf [In Dutch].

Steenken D, Voß S, Stahlbock R (2004) Container terminal operation and operations research. OR, vol 26. Spectrum, pp 3-49

UNCTAD. secretariat, based on Clarksons Research, Seaborne Trade Monitor, 2(5), 2015

Van der Voet, M., 2008. CO2-emissie door containeroverslagprocessen in de Rotterdamse haven. Master's thesis. Delft University of Technology, Delft

Van Duin R, Geerlings H (2011) Estimating CO2-footprints of container terminal port-operations. Int J Sustain Dev Plan 6(4):459-473

Weismann A (2010) Slow steaming - a viable long-lerm option? Wärtsilä Tech J 2:49-55 Retrieved from http://www. wartsila.com/docs/default-source/Service-catalogue-files/Engine-Services-\%2D-2-stroke/slow-steaming-a-viable-longterm-option.pdf?sfvrsn=0

Wilson I, Roach P (2000) Container stowage planning: a methodology for generating computerised solutions. J Oper Res Soc 51(11):1248-1255

Wong, A., Kozan, E., 2006. An intergrated approach in optimising container process at seaport container terminals. Proceedings of the second international intelligent logistics systems conference 2006, 23.1-23-14

Zhang H, Kim KH (2009) Maximizing the number of dual-cycle operations of quay cranes in container terminals. Comput Ind Eng 56(3):979-992

Submit your manuscript to a SpringerOpen ${ }^{\circ}$ journal and benefit from:

- Convenient online submission

- Rigorous peer review

- Open access: articles freely available online

- High visibility within the field

- Retaining the copyright to your article

Submit your next manuscript at $\gg$ springeropen.com 